\title{
Nursing student evaluations on the quality of mentoring support in individual, dual, and group approaches during clinical training: a prospective cohort study
}

\section{AUTHORS}

IVANA GUSAR MSN, RN, PhD candidate ${ }^{1,2}$

KRISTINA BAČKOV MSN, RN, PhD candidate ${ }^{1,3}$

ANDREA TOKIĆ PhD ${ }^{4}$

BORIS DŽELALIJA MD, PhD 2,3

ROBERT LOVRIĆ PhD, MSN, CNS, RN ${ }^{5}$
1 Faculty of Medicine, Josip Juraj Strossmayer University of Osijek, Osijek, Croatia

2 Department of Health Studies, University of Zadar, Zadar, Croatia.

3 General Hospital Zadar, Zadar, Croatia.

4 Department of Psychology, University of Zadar, Zadar, Croatia.

5 Nursing Institute "Prof. Radivoje Radić", Faculty of Dental Medicine and Health Osijek, Josip Juraj Strossmayer University of Osijek, Osijek, Croatia.

\section{CORRESPONDING AUTHOR}

ROBERT LOVRIĆ Nursing Institute "Prof. Radivoje Radić", Faculty of Dental Medicine and Health Osijek, Josip Juraj Strossmayer University of Osijek, Crkvena 21, HR-31000 Osijek, Croatia.

Phone: +385912000 973. Email rlovric@fdmz.hr

\section{ABSTRACT}

Objective: To examine how Bachelor of Science nursing students evaluate the quality of mentoring support during clinical training using three different types of mentoring approaches.

Background: The mentoring approach and the mentor-student relationship are important factors that determine nursing students' satisfaction with their clinical experience. However, there are significant differences in the approaches to mentoring in nursing, and there is no global consensus around a universal form of mentorship.

Study design and methods: The participants were first-year Bachelor of Science students $(n=86)$ divided into three groups exposed to three different mentoring approaches: Group 1 = dual (two mentors) group of students); Group 2 = individual (one mentor/ one student); Group 3 = group (one mentor/group of students). The validated Mentor Support Evaluation Questionnaire (MSEQ) was used to assess the quality of mentoring support.

Results: Students from Group 2 reported a significantly higher level of mentoring support quality $(P<0.01 ; M=4.8 ; S D=0.32)$ in comparison to students from Group $1(M=4.1 ; S D=0.66)$ and students from Group $3(M=3.32 ; S D=1.71)$.

Discussion: Nursing students exposed to different mentoring approaches vary in their reported quality of mentoring support. The highest quality of mentoring support was reported by students in the individual approach, and the lowest quality of mentoring support was reported by students mentored in a group of four to six students by 
a single mentor. In the individual approach, the students highlighted the continuous availability of the mentor, recognition of personal study needs, respect, safety, appreciation, and patience.

Conclusion: The approach to mentoring is an important factor that affects students' satisfaction with their clinical experience, and in return it influences achievement of final learning outcomes and professional development of students.

Implications for research, policy, and practice: The results of this study emphasize the importance individualizing the mentorship process in order to increase students' satisfaction and lead to more successful acquisition of knowledge, skills, and attitudes. These results also indicate the need to continuously monitor student evaluations of the quality of mentoring support and their overall satisfaction with the mentoring approach during clinical training. A future qualitative, longitudinal, mixed-methods study is recommended in order to investigate and describe the specific and (in)direct causes of student (dis)satisfaction in the mentorstudent relationship.

What is already known about the topic? There are different types of mentor approaches in nursing education. Comparisons of students' perceptions of mentor-student relationships in different mentoring approaches, such as individual, dual, or group mentoring, represent an under-researched area.

What this paper adds: Findings from this study provide evidence to better understanding the specific advantages and disadvantages of mentorstudent relationships in individual, dual, and group approaches from the students' point of view.

Keywords: mentor, mentorship, nursing students, satisfaction, training support

\section{INTRODUCTION}

Clinical experience is an essential component of all undergraduate nursing student degrees. ${ }^{1}$ The design and duration of clinical training (CT) received during Bachelor of Nursing programs vary throughout the world, ${ }^{2}$ and they sometimes even vary within the same country. ${ }^{3}$

Croatia, like most member countries of the European Union (EU), has implemented Directive 2005/36/EC into its education system. This directive defines that during the course of a three-year study and a minimum of 4,6oo hours, Bachelor of Science (BSc) nursing students in Croatia should spend at least 2,30o hours in a clinical environment under the supervision of a clinical mentor with a BSc and who is a qualified Registered Nurse (RN).4,5

Despite implementation of the EU directive, the mentoring system in the Republic of Croatia has not experienced significant changes. CT is mainly organized as a group mentoring approach, in which an individual approach to each students' needs is not possible. Usually five or six students have one common mentor who has a qualified BSc and is a registered nurse (RN). However, the group mentoring approach is still common throughout the world, ${ }^{13,25}$ and many studies have described a number of difficulties reported by students and mentors during this form of mentoring. ${ }^{1,3,17,42}$

In Croatia, the dual mentoring approach, when a student has two mentors for support and assistance, is rarely used except in situations of certain specific clinical exercises, and the individual approach is hardly used at all. ${ }^{6} \mathrm{~A}$ relevant indicator for the importance of the topic being researched is the fact that students spend a large number of hours with their mentor, during which they develop a relationship that is a key element in their satisfaction. ${ }^{5.7}$ The literature shows that the satisfaction of nursing students with their mentors is a frequently investigated topic around the world..$^{1,7-10}$ However, there is a lack of research and insufficient comparisons of students' perceptions of the mentor-student relationship in relation to different mentoring approaches such as individual, dual, or group mentoring in CT. The purpose of this study is to bridge this global gap and provide data to better understand the specific advantages and disadvantages of the mentor-student relationships in individual, dual, and group approaches from the student's point of view.

\section{BACKGROUND}

$\mathrm{CT}$ is a vital component of a nursing student's study program. ${ }^{1}$ It gives the student an opportunity to achieve competence in nursing practice. Despite recent definitions, ${ }^{11}$ Nowell et al. state there is global confusion in defining mentorship and the role of a mentor in nursing. ${ }^{12}$ There are different types of nursing CT programs around the world, $3,12,13$ but there is no single universal form and no agreement on how nursing students should be mentored. A similar situation is also present in the supervision of nurses. There is insufficient evidence to directly inform the selection of a specific model or way of supervising clinical training. ${ }^{14}$ Many differences in mentoring approaches exist. ${ }^{14-16}$ Numerous authors state that the level of satisfaction of nursing students depends on the quality of $\mathrm{CT}$ as well the mentor-student 
relationship and the quality of their interaction..$^{1,17-21}$ Students list their mentor's support and encouragement among the most important of their mentor's activities. ${ }^{22}$ This is especially important for nursing students during their first year of study who are at the initial stages of acquiring competency and need significant mentor assistance in most activities during $\mathrm{CT}^{23}$

According to the literature review conducted on different mentoring approaches, to date, the highest level of satisfaction is expressed by students who have a one-on-one mentor-student relationship. ${ }^{18,24}$ Research conducted by Warne et al. shows that the most important element in CT experience is the supervisory one-on-one relationship. ${ }^{18}$ Furthermore, in relevant research conducted on a sample of 418 nurses students, with the aim of assessing the level of nursing students' satisfaction with different mentoring approaches, researchers found that the mentoring approach significantly influenced the students' level of satisfaction, while variables such as age, gender, year of study, and duration of CT did not significantly influence their level of satisfaction. ${ }^{25}$

Nursing students' satisfaction in the present CT system is, an important factor to achieve expected learning outcomes and excellence in clinical education, 5 as well as retention in the profession. ${ }^{1}$ A mixed-methods study from Australia also found differences in students' satisfaction depending on demographic characteristics, ${ }^{1}$ which imposes the need to adjust mentoring practices. Research conducted in Malaysia in 2017 listed student satisfaction among six important factors of $\mathrm{CT}^{26}$ It is important to emphasize that nursing student participants in a previous mixed-methods study conducted in Croatia stated unfulfilled expectations from their mentor and the feeling of dissatisfaction during CT had a significantly negative effect on their behavior and demotivated them in terms of effectively performing CT tasks. ${ }^{5}$

Continuous examination of students' expectations and experiences during CT can improve the socio-educational environment and assist in creating, sustaining, and attaining the educational goals of students, ${ }^{27}$ in turn, this has a significant, positive impact on patient safety during CT. ${ }^{23}$ The need to improve upon mentoring systems is apparent. ${ }^{18}$ Despite numerous studies conducted around the world in the field of nursing education and mentoring, it is necessary to apply new studies and teaching strategies based on the new evidence. ${ }^{28,29}$ This study will investigate factors which ensure the best-valued elements in student-mentor relationships are potentially applied to other forms of mentoring work, which can be transferable in nature and have implications in the broader concept of mentoring in nursing education. This article intends to better understand student perceptions of the quality of mentoring support depending on the mentoring approach, and it will identify the factors and mentor behaviors that contribute to student satisfaction during CT.

Therefore, the main aim of this study was to examine how BSc students evaluate the quality of mentoring support during CT with respect to individual, dual, and group mentoring approaches.

\section{METHODS}

\section{PARTICIPANTS}

The participants in the study were first-year undergraduate nursing students $(n=86)$ in the 2018/2019 summer semester from a Higher Nursing Education Institution in Croatia, EU. First-year BSc nursing students were selected because they were in the initial phase of acquiring specific knowledge, skills, and attitudes, had high expectations of their mentors, had a lower level of independence than students in later years of study, required thorough mentoring guidelines and demonstrations of clinical procedures and techniques, and they had significant and complete mentoring support and assistance in some activities during CT. ${ }^{23}$ Out of the total of 86 participants in this study, 8 (9.3\%) were male and 78 (90.7\%) were female. Participants were 18 to 24 years old, and the average participant age (mean) was 20.3 years $(S D=1.2$ ).

\section{STUDY DESIGN}

This prospective cohort study was conducted during 6o hours of regular CT in hospital teaching departments. The selection criteria for departments to be included in the study stated they should not be an intensive care unit, and they had to be a clinical educational department where regular CT was performed.

Purposive sampling, based on research objectives, was performed according to the defined criteria. Hence, during the study, three groups of nursing students were examined (further referred to as Group 1, Group 2, and Group 3). Formation of groups and subgroups (SG), as well as their schedules in the clinical departments, was done based on regular training groups of first-year BSc students (Fig 1). Thus, given this was a homogenized sample of students, and given the effort to make the results of this study as close to reality as possible, students were divided into groups and subgroups according to an alphabetical list of surnames. This method is a common procedure for dividing students into exercise groups. Regular rotation of groups ensures that all students have the opportunity to clinically train in all departments during a particular course, semester, and academic year. Students from all three groups were exposed to different mentoring approaches. Group 1 had dual mentoring support (two mentors) during clinical training, Group 2 had individual, one-on-one mentors, and Group 3 had one mentor for the group of students. 


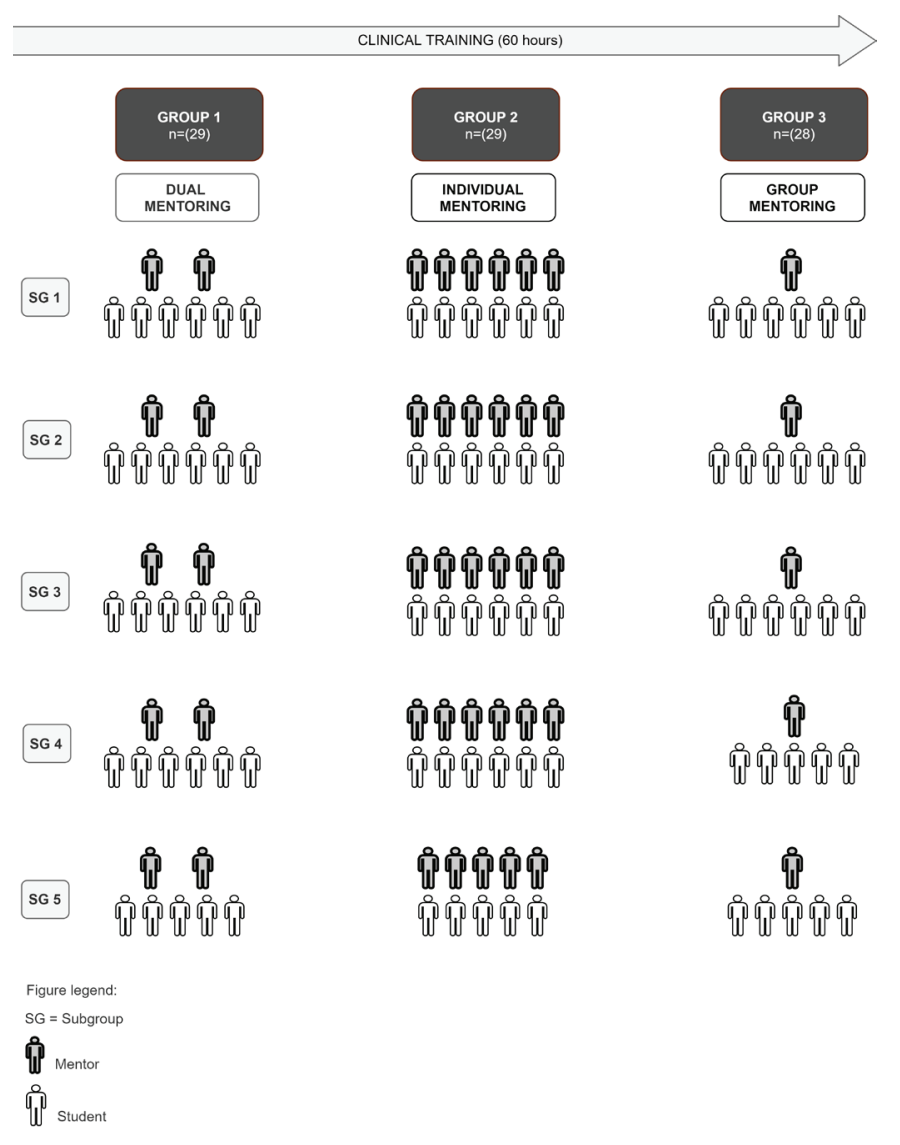

FIGURE 1: DESIGN OF STUDY - DISTRIBUTION OF GROUPS AND SUBGROUPS OF STUDENTS AND THEIR MENTORS DURING CT

The mentors in the study $(n=44)$ were BSc nursing graduates who were qualified RNs employed in the faculty base as head nurses and were also employees at the University. The mentors performed their regular work assignments in clinical departments (work organization and patient care) in the presence of students. Mentors assigned a patient to each student for continuous monitoring, planning, performing, and evaluating health care, as well as keeping clinical records. During execution of their work assignments, mentors simultaneously demonstrated the procedures to assigned students and provided them with explanations.

Participants in Group $1(n=29)$ performed their CT in a group of five to six students. They were mentored by two official mentors (dual mentoring approach) (Fig 1). Both mentors were involved in all phases of CT and worked according to a written CT operating plan. Mentors simultaneously participated in the preparation of students for CT, assessment of the condition and needs of patients, health care planning, demonstration of clinical skills, implementation of immediate patient care, evaluation of care, preparation of health care documentation, providing feedback to the student, and evaluation of cognitive, psychomotor, and effective student achievement according to defined elements and evaluation criteria.
The second group (Group 2) of participants $(n=29)$ was composed of students who performed their CT one-on-one with a faculty mentor (individual mentoring approach) (Fig 1). According to the aforementioned steps of the CT Operational Plan, mentors used an individualized and holistic approach of working with their students, beginning with individual preparation of the student for CT as well as working with and continuously monitoring their student to prepare them for the final evaluation of the student's knowledge, skills, and attitude. This kind of individualized supervision model has proven to be a crucial factor determining students' total satisfaction during their clinical training periods. ${ }^{25,30}$

Participants from Group $3(n=28)$ performed CT in a group of five to six students under the guidance of a single official mentor (group mentoring approach) (Fig 1). The mentor, while performing regular department assignments, conducted occasional joint meetings with the students. Thus, the mentor worked independently with all students in the group regarding the CT operating plan, from the preparation phase to the final evaluation phase, for all students. This mentoring approach is consistent with current regular CT curricula and is implemented at most Croatian nursing facilities. ${ }^{17}$

\section{DATA COLLECTION PROCEDURES}

Questionnaires with thorough explanations of all study details were forwarded through joint student e-mails (Group 1, Group 2, and Group 3) in the form of an online survey. Study participants filled their assessments/questionnaires immediately after 6 o hours of CT, and they sent their filled Google Forms questionnaires to the researchers anonymously via their student e-mail. All 86 (100\%) students completed the questionnaires voluntarily and completely.

\section{INSTRUMENT}

Following written consent from the original author of the questionnaire, the statements from the standardized Mentor Support Evaluation Questionnaire (MSEQ) were used to validate the mentoring support, as observed in another study. ${ }^{31}$ The instrument was originally designed by the Croatian Institute for Social Research primarily to support all participants in the mentoring process and to prevent the risk of poor-quality mentoring. Poor mentoring is very often a consequence of insufficient competency to perform mentoring duties..$^{31,32}$ MSEQ is based on the Croatian Qualifications Framework document, which regulates the entire system of qualifications and occupational standards at all education levels in the Republic of Croatia. ${ }^{33}$ The questionnaire explicitly focuses on the mentor's competencies and relationship with the students, and it is primarily intended to measure the level of student satisfaction with mentoring support and their general relationship with mentors. 
The original MSEQ consists of 39 statements in total, 25 of which are related to students' satisfaction with mentoring support and the mentor-student relationship during CT, while the 14 remaining statements relate to students' satisfaction with the delivery of academic courses/theoretical classes. Regarding the aim and focus of this study (mentorstudent relationship in the clinical environment), the 14 statements related to academic courses/theoretical class were removed from the questionnaire.

Principal component analysis with varimax rotation was performed with the remaining 25 statements from the original questionnaire in order to check the factoring structure. Using this procedure, one factor was extracted which explained $18.23 \%$ of the variance. The average intercorrelation among items was 0.73 , and Cronbach's alpha, measuring the internal consistency of the questionnaire, equaled 0.98 .

For the purposes of this study, a team of three nursing experts (two associate professors in nursing and one senior lecturer) was formed to verify the validity of the MSEQ. Responses to the questionnaire were evaluated on a rating scale (from $1=\mathrm{I}$ completely don't agree to $5=$ =I completely agree), in which a higher number represents a higher level of agreement with the statement in question as well as higher student satisfaction with the provided support and the mentorstudent relationship. Along with the aforementioned 25 items taken from the original questionnaire, the participants responded to questions related to general demographic information (e.g., gender and age).

\section{STATISTICAL ANALYSIS}

Statistical analyses of the acquired results were performed using Statistica 13 (TIBCO Software Inc., 2017). In the first phase of processing, the latent structure of the questionnaire was checked using principal component analysis with varimax rotation and with the Gottman-Kaiser criterion of factor extraction with a characteristic value greater than 1 . The reliability of the questionnaire was verified by Cronbach's alpha coefficient. In further analyses, descriptive data (arithmetic mean, standard deviation, and percentages) were calculated. Due to significant deviations in the distribution of total satisfaction of mentoring support and relationships with the mentor (as well as individual elements) among the three different groups, and with respect to a normal distribution, Kruskal-Wallis tests were used with post-hoc Rank tests.

\section{ETHICAL APPROVAL}

The ethical committee of the University approved the study at their regular meeting (IRB approval number: 2198-1-7937/19-02). All participants were informed of the aim of the study and other study details, and all voluntarily agreed to participate. Participants were able to stop participating at any time without any consequences. Anonymity of the participants during and after the study was guaranteed.

\section{RESULTS}

\section{STUDENT EVALUATIONS ON THE QUALITY OF MENTORING SUPPORT WITH RESPECT TO THE MENTORING APPROACH}

Since the psychometric characteristics of the applied MSEQ questionnaire were confirmed to have a single-factor structure and a very high level of reliability, the difference between the mean values of the total levels of satisfaction among the three examined groups of students was initially tested.

After analyzing student evaluations, the results indicated that students belonging to Group 2, mentored on the one-on-one approach (one mentor per student), ranked the quality of mentoring support as very high ( mean $=4.8 ; \mathrm{SD}=0.32$ ), and they were significantly more satisfied with their mentor support $\left(\mathrm{H}_{(2)}=33.69, \mathrm{P}<0.01\right.$; the Kruskal-Wallis test) when compared to students in Group 1 (mean $=4.1 ; \mathrm{SD}=0.66)$ and Group 3 (mean=3.3; SD=1.17) (Figure 2).



FIGURE 2: OVERALL LEVEL OF STUDENT EVALUATIONS OF MENTORING SUPPORT AMONG THREE GROUPS OF STUDENTS CONSIDERING THE MENTORING APPROACH $(\mathrm{N}=86)$

\section{SPECIFIC DIFFERENCES IN NURSING STUDENT EVALUATIONS ON THE QUALITY OF MENTORING SUPPORT WITH RESPECT TO THE MENTORING APPROACH}

Specific aspects of the evaluations and detailed differences among the three examined groups of students with regard to all 25 elements of the questionnaire are presented in Appendix A.

Quality of mentoring support among students in the first, second, and third groups was analyzed, and statistically important differences ( $\mathrm{P}<0.05$, Kruskal-Wallis) were found for all 25 questionnaire items (Appendix A).

Further pairwise examinations between the mean values 
of student evaluations for the examined groups showed significantly higher satisfaction among Group 2 students when compared to Group 3 students for all 25 questionnaire items ( $\mathrm{P}<0.05$, post-hoc rank test) (Appendix A).

The post-hoc rank test indicated a significantly higher satisfaction level among Group 2 students when compared to Group 1 students for 22 out of 25 questionnaire items $(\mathrm{P}<0.05)$; exceptions were for item number 6, "I arranged deadlines for certain tasks with my mentor" ( $\mathrm{P}=\mathrm{O} .244)$, item number 14 "The mentor followed my work and gave me feedback" $(\mathrm{P}=0.117)$, and item number 24 "I did not feel that my mentor was neglecting me due to other activities" $(\mathrm{P}=0.130)$ (Appendix A).

In contrast to the previous results, post-hoc analyses of Group 1 and Group 3 student satisfaction levels indicated that Group 1 students were significantly more satisfied in only 4 out of 25 questionnaire items. These items included number 2, "The mentor allows me to follow his/her work and explains his/ her professional procedures and decisions" ( $\mathrm{P}=0.014)$, item number 6, "I arranged deadlines for certain tasks with my mentor" ( $\mathrm{P}=0.039)$, item number 14 "The mentor followed my work and gave me feedback" ( $\mathrm{P}=0.047)$, and item number 24 "I did not feel that my mentor was neglecting me due to other activities" $(\mathrm{P}=0.024)$ (Appendix $\mathrm{A}$ ).

\section{DISCUSSION}

The results of this study clearly indicate that the three groups of nursing students exposed to different mentoring approaches significantly differed in the reported quality of mentoring support, which is in accordance with other research. ${ }^{8,13,25,34}$

The highest-quality level of mentoring support (average $=$ 4.8) was found in Group 2 students, who were mentored by a single official mentor. The lowest grade in Group 2 (4.5) was higher than the highest grade in Group 1 (4.4), and especially in Group 3 (3.9). Students were very satisfied with the one-on-one mentoring approach (4.8). In the individual approach, students experienced continuous availability of their mentor, recognition of personal study needs, respect, safety, appreciation, and patience. These results were also confirmed in recent international studies, in which only $25 \%$ of the sample had an individualized supervisory relationship and stated that these students were most satisfied with the individual mentor-student relationship. ${ }^{25}$ The highest student satisfaction in the individual mentoring approach has also been confirmed by other studies around the world. . $^{8,10,34 \text {, }}$

Previous studies have emphasized that the one-on-one mentoring approach is the most effective in clinical practice. ${ }^{25,30}$ In the Crawford qualitative study, results showed that students perceived their relationship with their mentor as pivotal to their development as a nurse. ${ }^{8}$ They developed supportive and caring relationships, which resulted in students expressing deep respect for their mentors and vice versa. Saarikoski states that the individual mentor-student relationship is a key element in satisfaction and professional socialisation, and they describe positive effects of individual mentoring such as continual feedback, respect, and confidence regarding student satisfaction and the learning outcomes. 24,35

The next group of students according to the quality of mentoring support (mean=4.1) was Group 1, where students were mentored by two employees of the faculty base. Students from Group 1 gave the lowest scores for guided learning and critical thinking. In addition, they did not perceive their mentor as a role model. On the other hand, Group 1 participants emphasized the possibility of following their mentor's work, common agreement and adherence to the agreement, feedback information, and the feeling that they were not being neglected. Dual mentoring may be an appropriate solution to meet the needs of the students, including additional academic and psychosocial support and promoting a positive attitude. ${ }^{36,37}$ The importance of these student statements were described in the Crawford study, in which students reported common agreement and appreciation in their relationships with mentors. The importance of feedback was also emphasized by a student's statement "no news is bad news". ${ }^{8}$ The same results in the literature review state that feedback has a purpose to improve nursing students in their practice. ${ }^{38}$ The results in our study can be explained by the fact that two mentors had regular work commitments and, therefore, did not have enough time to provide individual support to students, but they were able to pay enough attention to procedures and student behavior, which is extremely important according to students' expectations. ${ }^{5}$

The lowest quality of mentoring support ( mean=3.3) was found in Group 3, where students were mentored in a group of four to six students by a single official mentor. Group 3 students indicated very low levels of satisfaction with mentoring support and that students did not acquire the necessary skills, were unable to think critically, and did not perceive their mentor as a role model. Clinical training in real environments needs to provide students the possibility to integrate theory and practice and to help them acquire necessary clinical competencies and skills in decision making, critical thinking, ethical reasoning, and professional communication. ${ }^{39,40}$ Salamonson et al. conducted their studies in four universities in Australia and also confirmed students showed some negative experiences during CT such as lack of time to teach, excessive nursing workload, and lack of engagement, and they expressed dissatisfaction with the mentors' focus on learning rather than their needs. ${ }^{1}$ Therefore, mentors as clinical and pedagogical professionals should encourage critical thinking and be a role model to their students. ${ }^{5}$ Finally, students in this study were not 
satisfied with this form of mentoring. Similar results were shown in another study where group supervision was dominant in the sample. ${ }^{25}$ Antohe et al. stated that it is necessary to shift the group supervision model towards individual supervision. Group mentorship models in nursing pose a significant challenge worldwide since mentors simultaneously have to perform dual roles. ${ }^{23}$ The assumption is that, in group mentorship, the mentors do not have the capacity to develop satisfactory interpersonal relationships with their students, which has proven to be, in many studies conducted so far, the most important characteristic as well as the most demanding category in mentorship. ${ }^{41}$ In a systematic review, Jokelainen et al. also reported students want to be treated as individuals during placement learning. ${ }^{15}$

From the aforementioned results, it is clear that the main detractors of a more effective mentorship were the mentor's regular workload, lack of time, and the number of students assigned to a single mentor., ${ }^{1,3,42}$

Post-hoc rank tests of the differences among participants from all three groups also recognized significantly higherquality mentoring support for all 25 questionnaire items in Group 2 participants, when compared to Group 3 participants, and for 22 questionnaire items when compared to Group 1 participants. The absence of a significant difference in the three mentioned items can be interpreted by the notion that the mentor from Group 2, despite their individual approach, did not have enough time for the students because of their regular work assignments at the department. Moreover, both mentors in Group 1 had more time dedicated to students, but the results from other questionnaire items suggest that it was still insufficient. Group 1 participants gave significantly higher ratings than the participants from Group 3 in only four items, which can be interpreted by the overload of a single mentor from Group 3 with his own work assignments and group of students. It is evident that the pairwise test between Group 2 and Group 1 identified a single mentor in a group of students as a key deterrent for a more effective mentorship, i.e., in this case, a form of mentorship which would provide a higher level of student satisfaction.

The results clearly indicate that students cannot be seen as a group, but rather as individuals. ${ }^{43}$ Mentor duties, when incorporated with the regular duties of a nurse, receive insufficient dedication during regular working hours, especially when it comes to a group of students. ${ }^{23,44}$ Previously quoted research confirms that the level of student satisfaction depends on their perception of dedication and monitoring of their mentor. Students with mentors that continuously monitor them have a higher level of satisfaction in comparison to the students without continuous monitoring. ${ }^{25}$ The results give clear recommendations to tailor education according to students' needs. ${ }^{7}$ D'Souza et al.psychomotor, and affective skills in the Middle East. Objective: The aim of the paper is to assess the satisfaction with and effectiveness of the clinical learning environment among nursing students in Oman. Design: A cross-sectional descriptive design was used. Setting and Participants: A convenience sample consisting of 310 undergraduate nursing students was selected in a public school of nursing in Oman. Methods: Ethical approval was obtained from the Research and Ethics Committee, College of Nursing in 2011. A standardized, structured, validated and reliable Clinical Learning Environment Supervision Teacher Evaluation instrument was used. Informed consent was obtained from all the students. Data was analyzed with ANOVA and structural equation modeling. Results: Satisfaction with the clinical learning environment (CLE stated that mentors need to change their educational strategies and reorganize CT for nurses in order to provide better mentoring support and learning opportunities, thus increasing the level of student satisfaction. ${ }^{34}$ In circumstances where it is not possible to provide individual mentoring approaches to meet the needs of students, it is necessary to pay special attention to ensure efficient use of mentors' time. In addition, mentors should take into account the fact that good teaching preparation is important, but it is more important to recognize their students' needs.

\section{STUDY LIMITATIONS AND RECOMMENDATIONS FOR FUTURE RESEARCH}

This study included only a sample of nursing students at the University in the Republic of Croatia in order to facilitate implementation and ensure more effective control of the study.

In Group 2, only one mentor was included in the mentoring process, and this might be considered negative given the students dependence on the knowledge and competencies of only one person.

Future work should identify occasions where the individual approach is not possible, and should identify how the most valued elements from the individual mentoring approach might be applied to other mentoring approaches.

A qualitative, longitudinal, mixed-methods study monitoring the same participants is being planned, which will provide student interviews that will describe the specific and (in) direct causes of student (dis)satisfaction in the mentorstudent relationship and mentor support in more detail.

\section{IMPLICATIONS FOR RESEARCH, EDUCATION AND CLINICAL TRAINING}

Results of this study offer new insights, which can help clinical facilities and educational institutions understand student expectations during clinical training and identify and moderate the factors that impact their satisfaction during CT. Continuous examination of the expectations and experiences of students during CT can improve the socioeducational environment and assist in creating, sustaining, 
and attaining the educational goals of students, which, in turn, has a significant, positive impact on patient safety during CT. This study investigated factors that can ensure the best-valued elements in student-mentor relationships are potentially transferred to other forms of mentoring work, which can be transferable by nature and provide implications in the broader concept of mentoring in nursing training. This article provides a better understanding of students' perceptions of the quality of mentoring support depending on the mentoring approach, and it identified the factors and mentor behaviors that contribute to student satisfaction during CT.

\section{CONCLUSIONS}

This study found that students who experienced a one-onone mentoring approach were most satisfied with their mentoring support. According to evaluations on the quality of mentoring support, the next group of students ranked were those mentored as a group by two mentors. The least satisfied with their mentoring approach and support were the students mentored as a group by a single official mentor. The results of this study indicate that having to perform regular department duties along with mentoring a group consisting of more students detracted from the quality of mentorship, and what surfaced as a key problem was mentor overload caused by multiple simultaneous duties. Therefore, the results of this study emphasize the importance of individualizing the mentorship process in order to increase student satisfaction and promote successful acquisition of knowledge, skills, and attitudes. These results indicate the need to continuously monitor student evaluations regarding the quality of mentoring support and their overall satisfaction with the mentoring approach during CT.

The results indicate very low satisfaction in the quality of mentoring support in the dual and group mentoring approaches. The students were not satisfied, they did not acquire the necessary skills, they were unable to think critically, and they did not perceive their mentor as a role model. All of the above can have a negative impact on the achievement of learning outcomes, student competencies, and the quality of patient care.

\section{Role of the funding source:}

This study received no specific grant from any funding agency in the public, commercial, or not-for-profit sectors.

\section{Conflicts of Interest: none.}

Ethical Approval Details: Ethical committee of the University of Zadar approved the study. All participants were informed of the aim of the study, and voluntarily agreed to participate in the study. Anonymity of participants during and after the study was guaranteed.

\section{REFERENCES}

1. Salamonson Y, Everett B, Halcomb E, et al. Unravelling the complexities of nursing students' feedback on the clinical learning environment: A mixed methods approach. Nurse Educ Today. 2015; 35(1):206-11.

2. Walker $S$, Dwyer T, Broadbent $M$, et al. Constructing a nursing identity within the clinical environment: The student nurse experience. Contemp Nurse. 2014; 49:103-12.

3. Kenny P, Reeve R, Hall J. Satisfaction with nursing education, job satisfaction, and work intentions of new graduate nurses Nurse Educ Today. 2016; 36:230-5.

4. Crombie A, Brindley J, Harris D, et al. Factors that enhance rates of completion: what makes students stay? Nurse Educ Today. 2013; 33(11):1282-7.

5. Lovrić R, Prlić N, Barać l, et al. Nursing students' expectations and evaluations of mentors' competences and mentors' self-evaluations as indicators of mentoring process quality. American Journal of Nursing Science. 2017; 6(5):382-6.

6. Lovric R, Prlic N, Zec D, et al. Students' assessment and selfassessment of nursing clinical faculty competencies: important feedback in clinical education. Nurse Educ. 2015.

7. Papastavrou E, Dimitriadou M, Tsangari $H$, et al. Nursing students' satisfaction of the clinical learning environment: a research study. BMC Nurs. 2016; 15(1):1-10

8. Crawford M, Dresen S, Tschikota S. From getting to know you to soloing: the perceptor-student relationship. NT Research. 2000; 5(1):5-19.

9. Myall M, Levett-Jones T, Lathlean J. Mentorship in contemporary practice: The experiences of nursing students and practice mentors. J Clin Nurs. 2008; 17(14):1834-42.

10. Lamont S, Brunero S, Woods KP. Satisfaction with clinical placement - The perspective of nursing students from multiple universities. Collegian. 2015; 22(1):125-33.

11. Matin SA. Understanding effective mentoring in nursing education: the relational-reliant concept." JOJ Nursing \& Health Care. 2017; 2(5):1-3.

12. Nowell L, Norris JM, Mrklas K, et al. A literature review of mentorship programs in academic nursing. J Prof Nurs. 2017; 33(5):334-44

13. Franklin N. Clinical supervision in undergraduate nursing students: a review of the literature. e-Journal of Business Education and Scholarship of Teaching. 2013; 7(1):34-42.

14. Pollock A, Campbell P, Deery R, et al. A systematic review of evidence relating to clinical supervision for nurses, midwives and allied health professionals. J of Adv Nurs. 2017; 73(8): 1825-37.

15. Jokelainen M, Turunen $H$, Tossavainen $K$, et al. A systematic review of mentoring nursing students in clinical placements. $\mathrm{J}$ of Clin Nurs. 2011; 20(19-20):2854-67.

16. Walker $S$, Dwyer T, Moxham L, et al. Facilitator versus preceptor: which offers the best support to undergraduate nursing students? Nurse Educ Today. 2013; 33(5):530-5.

17. Lovrić R, Prlić $N$, Milutinović $D$, et al. Changes in nursing students' expectations of nursing clinical faculties' competences: a longitudinal, mixed methods study. Nurse Educ Today. 2017.

18. Warne T, Johansson UB, Papastavrou E, et al. An exploration of the clinical learning experience of nursing students in nine European countries. Nurse Educ Today. 2010. 
19. Agius NM, Wilkinson A. Students' and teachers' views of written feedback at undergraduate level: a literature review. Nurse Educ Today. 2014; 34(4):552-9.

20. DeBourgh GA. Predictors of student satisfaction in distancedelivered graduate nursing courses: What matters most? $J$ of Prof Nurs. 2003; 19(3):149-63.

21. Vinales JJ. The mentor as a role model and the importance of belongingness. Br J of Nurs. 2015

22. Foster H, Ooms A, Marks-Maran D. Nursing students' expectations and experiences of mentorship. Nurse Educ Today. 2015; 35(1):18-24.

23. Lovrić R, Prlić N, Barać l, et al. Specificities and differences in Nursing Students' perceptions of nursing clinical faculties' competences. J of Prof Nurs. 2014.

24. Saarikoski M, Marrow C, Abreu W, et al. Student nurses' experience of supervision and mentorship in clinical practice: a cross cultural perspective. Nurse Educ Pract. 2007; 7(6):407-15.

25. Antohe I, Riklikiene O, Tichelaar E, et al. Clinical education and training of student nurses in four moderately new European Union countries: assessment of students' satisfaction with the learning environment. Nurse Educ Pract. 2016; 17:139-44.

26. Mansutti I, Saiani L, Grassetti L, et al. Instruments evaluating the quality of the clinical learning environment in nursing education: a systematic review of psychometric properties. Int J Nurs Stud. 2017.

27. Zinkeng M, Molesy A. Dynamics of socio-educational environment on the attainment of students' educational aspirations. Greener J of Psych and Counsel. 2019; 3(1):28-32.

28. Oermann HM, Gaberson K, Shellenbarger T. Clinical teaching strategias in nursing. 5th Ed. Springler Publishing Company. Clinical Teaching Strategies in Nursing. New York; 2018.

29. Vierula J, Stolt M, Salminen L, et al. Nursing education research in Finland - a review of doctoral dissertations. Nurse Educ Today. 2015

30. Mažionienè A, Staniulienè V, Gerikienè V. The clinical learning environment: the attitude of undergraduate student nurses towards mentorship at hospitals in Lithuania. CBU International Conference Proceedings. 2018; 6:659-66.

31. Vidović V, Vuković MB, Matić J. IDIZ-ov priručnik za mentoriranje mladih istraživača. Zagreb: Institut za društvena istraživanja; 2014. 35p. Available from: https://www.ffri.uniri.hr/ files/dokumentifakulteta/IDIZ-ov prirucnik za mentoriranje.pdf

32. Lovrić R, Prlić N, Milutinović $D$, et al. Changes in nursing students' expectations of nursing clinical faculties' competences: a longitudinal, mixed methods study. Nurse Educ Today. 2017; 59:38-44.

33. Croatian Qualification Framework Act. 22/13,41/16,64/18. Republic of Croatia; 2013. Available from: https://narodnenovine.nn.hr/clanci/sluzbeni/2013 0222 359.html

34. D'Souza MS, Karkada SN, Parahoo K, et al. Perception of and satisfaction with the clinical learning environment among nursing students. Nurse Educ Today. 2015; 35(6):833-40.

35. Saarikoski M. Development and validation of the CLES evaluation scale. Nurs Care. Turku, Finland: University of Turku; 2002.

36. Abdolalizadeh P, Pourhassan S, Gandomkar R, et al. Dual peer mentoring program for undergraduate medical students: exploring the perceptions of mentors and mentees. Med J Islamic Rep Iran. 2017; 31(1):2-6.
37. Sambunjak D, Straus SE, Marusic A. A systematic review of qualitative research on the meaning and characteristics of mentoring in academic medicine. J Gen Intern Med. 2010; 25(1):72-8.

38. Agius NM, Wilkinson A. Students' and teachers' views of written feedback at undergraduate level: a literature review. Nurse Educ Today. 2014.

39. Mikkonen K, Elo S, Miettunen J, et al. Development and testing of the CALD s and CLES+T scales for international nursing students clinical learning environments. J Adv Nurs. 2017; 73(8):1977-2011.

40. Pitkänena S, Kääriäinen M, Oikarainena $A$, et al. Healthcare students' evaluation of the clinical learning environment and supervision - a cross-sectional study. Nurse Educ Today. 2018; 62:143-9.

41. Salminen $L$, Stolt $M$, Saarikoski $M$, et al. Future challenges for nursing education - a European perspective. Nurse Educ Today. 2010; 30(3):233-8.

42. Neshuku H, Amukugo HJ. Experiences of registered and student nurses regarding the clinical supervision in medical and surgical wards: develop an educational programme to support registered nurses. Int J Med. 2015; 3(2):87.

43. Lilja Andersson P, Edberg AK. Swedish nursing students' experience of aspects important for their learning process and their ability to handle the complexity of the nursing degree program. Nurse Educ Today. 2012; 32(4):453-7.

44. Löfmark A, Thorkildsen K, Råholm MB, et al. Nursing students' satisfaction with supervision from preceptors and teachers during clinical practice. Nurse Educ Pract. 2012; 12(3):164-9. 